\title{
A narrative approach to understand students' identities and choices
}

Holmegaard, Henriette Tolstrup; Ulriksen, Lars; Madsen, Lene Møller

Published in:

Understanding student participation and choice in science and technology education

Publication date:

2015

Document version

Peer reviewed version

Citation for published version (APA):

Holmegaard, H. T., Ulriksen, L., \& Madsen, L. M. (2015). A narrative approach to understand students' identities and choices. In E. K. Henriksen, J. Dillon, \& J. Ryder (Eds.), Understanding student participation and choice in science and technology education (pp. 31-42). Springer Science+Business Media. Education 


\title{
3 A narrative approach to understand students' identities and choices
}

\author{
Henriette T. Holmegaard, Lars Ulriksen and Lene Møller Madsen \\ University of Copenhagen, Department of Science Education, Øster Voldgade 3, DK-1350 \\ Copenhagen C, DENMARK. E-mail: HTHolmegaard@ind.ku.dk
}

\begin{abstract}
This chapter demonstrates how narrative theory in general, and narrative psychology in particular, contribute to understand how students make meaning of their choice of post-secondary studies. In particular two central ideas within the theory are unfolded; the concept of identity and the concept of time. The applicability of the theory is discussed using empirical examples. The chapter argues that a narrative approach provides an understanding of choice of study as continuous processes where individuals work on their identities in terms of negotiating and constructing a coherent choice-narrative. As a consequence future studies need to be careful when interpreting student statements about how they always wanted to study a particular subject. Narrative psychology illustrates how we need to contextualize this 'always' in terms of the students' current position, cultural context and meaning making. At the end of the chapter consequences for future research are discussed as well as how this approach to students' choices of study contributes to our understanding of students' science, technology, engineering and mathematics (STEM) choices.
\end{abstract}

Keywords: Narrative psychology, Negotiations, Identity construction, Student choice, choice-process.

\section{Narrative research to understand the complexity in students' choices}

Since the 1970s, research in students' educational choices has been carried out to inform policymakers and to help them predict, plan and affect student enrolment, recruitment activities and student marketing (Paulsen, 1990). As a consequence, large-scale quantitative studies have been carried out to identify and map the components that affect young people's educational choices, some with comprehensive models of student choices as an outcome. The Eccles model presented in Chapter 2 is such an example (Eccles \& Wigfield, 2002). However, whilst this extensive research has provided a reasonably clear picture of these components (Bergerson, 
2010), as higher education institutions are facing an increasingly diverse student body (Reay, David, \& Ball, 2005) there is a call to move towards more qualitative research that explores how the students themselves handle and make meaning of their choices (Archer et al., 2010; Hsu, Roth, Marshall, \& Guenette, 2009). In the period 2000-2010 research addressing this purpose has been carried out studying how students' identities relate to their choice of education (Archer et al., 2010; Brunila et al., 2011; Illeris, Katznelson, Simonsen, \& Ulriksen, 2002; Schreiner, 2006; Schreiner \& Sjøberg, 2007). A key finding in this research is that for the students it is not only a question about what they want to study, but also of who they wish to become, i.e. of constructing an attractive identity (Illeris et al., 2002). However, there is still a call for qualitative studies 'that can delve into the how and why questions that blur our clear understanding of how students experience the process of making post-secondary education decisions' (Bergerson, 2010).

As we will show, narrative theories in general and narrative psychology in particular provide new insights in the study of upper secondary school students' choices of, and transition into, higher education. The focus is on how the students in their construction of an identity balance and negotiate the options they recognize as available and suitable, and how these acts of balancing, negotiating, and constructing eventually lead them to decide whether or not to enter a STEM study programme. In this chapter, we will present two core ideas within the theory that influence our comprehension of students' choices; namely the concept of identity as an ongoing process, and the concept of time; in particular how identities move across time and how individuals make meaning of the present by negotiating what was before (in retrospect) and what is expected in the future (prospective).

The examples used in the chapter are drawn from a longitudinal study presented in Chapter 15, where 38 students in Denmark were followed for three years from the end of upper-secondary school. All of the students had attended an upper-secondary programme with a particular emphasis on science and (for some of the students) technology. (For a more extensive presentation of the method see Holmegaard, 2013).

\section{Narrative theories and narrative psychology}

Awareness of narrative structures has a long history in the research literature (Czarniawska, 2004). However, in the 1970s 'the narrative turn' and the emphasis on person-centred approaches introduced a variety of narrative theories across the social sciences (Andrews, Squire, \& Tamboukou, 2008). The research community's interest in narrative research was initiated by the philosopher Paul Ricoeur $(1976,1990)$ and his ideas on understanding narratives and experiences as storied structures. His thoughts have been influencing the development of narrative theories in various disciplines such as literature, rhetoric, psychology, political science 
and anthropology. Despite the different nature of the disciplines, narrative theories can be divided into three main categories. One category consists of theories focusing on narrative syntax or structures and can be applied to understand storylines in for example films, literature and personal narratives. A second category consists of approaches with a focus on meaning making in narratives (semantics or content). Finally, a third category is made of theories focusing on the narrative in a particular context (for instance, studying narrative configurations in particular historical periods) (Andrews et al., 2008; Smith \& Sparkes, 2008). In this book the chapters drawing on narrative research belong to the second category, since they take their point of departure in an analysis of the way students make meaning of their experiences.

Within psychology, the use of narrative theories followed what is known as the 'crisis in psychology' in the 1970s, breaking with the widespread experimental tradition and moving towards new criteria for conducting science (Sarbin, 1986). By examining and measuring the self as traits, abilities, and personality, other theoretical positions arose that described identity as something multifaceted and complex and being produced in a social and cultural context. Identity as a research object moved from the lab into social situations now requiring qualitative research methods (Potter \& Wetherell, 1987).

Narrative psychology is far from a field characterized by consensus. The approach covers various ideas of what narratives are and how they should be studied. However, there is agreement in terms of the understanding that 'identities and selves are shaped by the larger socio-cultural matrix of our being-in-the-world and, at the least, narrative implies a relational world' (Smith \& Sparkes, $2008 \mathrm{p}$. 3 ). However, the theoretical positions vary in terms of how the relation between identity/selves on the one side and, on the other side, socio-cultural surroundings are balanced in a spectrum ranging from 'thick individual' and 'thin social' to 'thin individual' and 'thick social' (Smith \& Sparkes, 2008). In the former, theories perceive individuals to possess a self and highlight narratives as the coherent story constructed from the inside and out: 'That the storied accounts we hear reflect an inner sense of narrative identity' (McAdams, 2005 p. 129). Some of the theoretical positions on this side of the spectrum are inspired by psychoanalytic ideas. The other side of the spectrum (thin individual and thick social) emphasises the production of narratives within a socio-cultural context. This perspective is inspired by post-structuralist and social-constructivist theories:

(...) identities are viewed as multiple, fragmentary, unfinished, always changing. They are performative, destabilized and deferred, rather than an inherent, unified property of the individual. (Smith \& Sparkes, 2008 p. 24)

In the middle of the spectrum are theories that take both the social and the individual perspectives into account. These theories perceive narrative identities on the one hand to be constructed inter-subjectively in interaction with others, constituted by political power-laden processes and social relationships, and mediated 
through institutional structures (Ezzy, 1998). On the other hand, they find that each individual has different resources and possibilities available; each subject is involved with specific persons, capacities, and circumstances (Crossley, 2000) and carries with them a history. These theories in the middle of the spectrum, therefore, both look into the structures and cultures in the environment where the narratives are produced, but also how narratives are related to the students' own and the students' surroundings sense of self, i.e. the perception of who he/she is, how she/ he will become recognised as him/herself (Bruner, 1990).

The narrative theories applied in this book position themselves ranging from the middle of the spectrum (Chapters 7 and 15) to a 'thick socio cultural' and 'thin individual' position (Chapter 17). The chapters vary in how they use narrative theory and narrative psychology, as theory, method or methodology. Chapter 7 and 15 use narrative psychology as a methodology, that is, both as the underlying conceptual framework for understanding the notion of identity, but it also guiding the way interviews are conducted and the tools for analyzing them. Chapter 17 reads narrative psychology into a broader post-structuralist framework.

In the following we wish to unfold the central concepts within narrative psychology as perceived from the middle of the spectrum introduced above, and with concrete examples to illustrate how these concepts can be applied to empirical data.

\section{Identity, meaning and choice}

When students are about to choose what to study after upper-secondary school they undergo a meaning making process where they struggle to make sense of who they are and who to become (Illeris et al., 2002; Schreiner, 2006). Within narrative psychology this meaning making process is a central concept. Not only do narratives say something about events and experiences, but more precisely they offer an approach to study how individuals understand these events and experiences and what meaning they ascribe to them. Meaning making is understood as a way of structuring the world (Ulriksen et al. 2013). Through narratives, the complexity in our experiences of the world is fixed into a sense of coherence and causality in terms of what caused the events and the experiences and why. A central question, then, is how this meaning making takes place. In this chapter we argue that meaning making is both embedded in the cultural context where the narratives take place, and constructed in relation to the individuals' own and their surroundings' sense of the individual's self. Individuals cannot freely invent narratives that aren't recognizable in terms of these two central aspects - the culture and other people. 
We understand our lives as a single progressive story, and our identities are cumulative over time (Polkinghorne, 1988). This means that we conceive of others, and ourselves, as possessing a coherent self. Consequently, there is a limit to how flexible and fluid our narratives can appear. Therefore, we present ourselves in a way that appears reliable and valid to other people's expectations of meeting a stable self. This is what Bruner calls 'folk psychology as an instrument of culture' (Bruner, 1990). Therefore, the notion of identity on the one hand must be understood as possessing a culturally embedded stability, but on the other hand as constantly changing, flowing backwards and forwards, a continuous process in which we keep on working to retell ourselves: 'We are always lost in transitions' (Quinn, 2010).

Individuals are made and at the same time make themselves recognisable through narratives. The self, then, is a meaning rather than a substance or a thing (Polkinghorne, 1988 p. 152). Narratives are then both what structures the world, and what relates us to it. Narratives are a way of framing events, beliefs, and desires into a coherent story. Therefore, when applying narrative psychology to studying students' choices we learn about how they ascribe meaning to their choice but also gain access to how they relate themselves to it. We label this process a 'choice narrative'. This covers students' work on their identities to construct a narrative of why they considered choosing a particular study programme and how they relate themselves to it. To illustrate how this identity work takes place we present part of the choice-narrative of Louise. In an interview just before completing upper-secondary school, Louise explained why she considered choosing to study international business at university:

I really can imagine myself in a business-suit as a leader. I am always like a leader in my class when working in groups but also in general. I am also the one who takes care of coordinating when we meet outside class. (...) I think the kind of working culture and job will suit me well, getting to travel a lot and live in the city (...) I think I will have a lot of opportunities later on if I study business (Louise, upper secondary school)

Louise presents an example of how the students construct a narrative by relating themselves to their expectations of what kind of future they could see becoming available through this particular study programme. During most of the interview, Louise explained how physics was her favourite course, especially the abstract parts, but, contrary to business, Louise found it hard to see any attractive identity if she were choosing a STEM programme at higher education:

\footnotetext{
I've always thought I was going to study engineering, physics or nanotechnology or something. But I just think it will become too boring for me. I like being around people. But physics is just so very fixed. Unless you are really clever, and get to do research in the things that are not explored yet - it is fixed (...) It is just too superficial, really. There are no perspectives of personal development in it, and I could not see myself not having anything to do with other people at all. (Louise, upper secondary school)
}

Louise makes meaning of a future study programme and career as contexts where you need to develop yourself, be around people, and relate to the content in a way 
that does not appear to be fixed and superficial. Louise finds it more likely to have those requirements met in the study of international business than of physics. Through her choice-narrative she works on relating herself to her expectations of what business will be like, both within the study programme at higher education but also the career opportunities she expects will be available.

Through narrative psychology we do not just learn about how students make meaning and how they relate themselves to that meaning. We also learn about how choosing what to study is embedded in culturally shared understandings. This is illustrated in the following quote from the interview with another student, Filip. For Filip, choosing what to study is perceived to be his own personal task:

Personally, I'm sort of uneasy about being influenced by a career counsellor. He is not neutral. It would be nice if he was, but nobody would be neutral. A counsellor also has an idea about what would be good to study. I would be nervous, then, to be influenced by it (Filip, upper secondary school).

Filip's idea of having to make his choice by himself also suggests his notion of how a proper choice should be made, namely without the influence of anyone else. Furthermore, the idea of making one's choice by oneself is an example of how the students construct their choices in culturally embedded truisms. The notion of the autonomous choice is not challenged by the students, and even though they are nervous or unsure about the choice, it does not fit well with asking an unknown counsellor for help.

In narrative psychology, narratives are understood as culturally embedded: 'We live publicly by public meanings and by shared procedures of interpretation and negotiation' (Bruner, 1990 p. 13). If narratives are to be understood as sensible and recognized by the students' surroundings, they need to be embedded in cultural ways of performing a choice-narrative, and further be consistent with what the student and the student's surroundings consider as a proper match for the particular student:

We begin with the premise that identities are lived in and through activity and must be conceptualized as they develop in social practice. But we are also interested in identities as psychohistorical formations that develop over a person's lifetime, populating intimate terrain and motivating social life.

(Holland, Lachicotte, Skinner, \& Cain, 1998, p. 5)

We now turn to how the culturally embedded stability in students' identities affects students' choices. When choosing what to study by the end of uppersecondary school, the students construct narratives that align their expectations of a certain study programme with who they perceive themselves to be. An example is Ian. He was encouraged by his parents to choose his future study programme according to his interests, but when he told them that he considered studying law, his parents questioned whether becoming a lawyer was an attractive choice for him after all. His parents found it hard to see how studying law would suit the person they recognised him to be. From their perspective lawyers were not decent people and could not be trusted, which conflicted with their perceptions of Ian. 
Therefore his choice narrative of studying law was not recognized as proper and suitable for him. Ian eventually chose to study bio-chemistry, a choice which particularly his mother, herself a bachelor of biomedical laboratory science, found sensible and suitable. Another student put it like this:

To me choosing the right thing is about getting some kind of acceptance from my family. I also consider what my friends can picture me doing. As when I say 'I would like to study medicine' they reply: 'that is a great idea. We also picture you as a medical doctor

(Asger, upper secondary school).

Even though the choice of study is being considered a responsibility of the individual (and the responses in the IRIS Q questionnaire suggest that the students themselves describe the influence from families and other persons on their choice as limited, cf. Chapter 9), the students' narratives show that the choice-narratives are constantly tried out and negotiated in the students' social relations where they are informed, adjusted and revised based on how these social relations meet and recognize the choice-narratives and whether they are considered suitable to who they expect the student to be. This requires the students to make their choicenarratives recognizable, even though not all students present their choicenarratives to their friends and families as explicitly as in the examples above. But most students do need to become recognized by their circle of acquaintances as somebody who is about to make a sensible and well-reasoned choice that suits who they are. Hence, they need to construct a choice-narrative that corresponds with who they are and who their surroundings perceive them to be.

Constructing a choice narrative implies identity-work for the student to gain a sense of match between what the student expects a certain programme to be like, the student's expectations of who to become, and a choice-narrative that combines past narratives with future horizons. In the next section we will show how narrative psychology provides a tool to perceive this identity-work as a continuing process rather than a specific decision point.

\section{Choice as a process; the concept of time}

In this section we provide empirical examples of what this process of choosing what to study looks like, and how the concept of time can be used as a tool to explore students' choices.

Christine was really interested in architecture and design, and strongly considered studying engineering. She also thought of studying mathematics at university, but she had difficulties with seeing other prospects of studying mathematics than becoming a teacher, which she did not consider to be an attractive choice: 
I'm convinced that I would kill the children before I got to teach them anything (laughs). I don't think I would fit that well as a teacher (...) Now that I think about it I don't think I could stand becoming a teacher. (Christine, upper secondary school).

Five months later, Christine sent the researchers a text-message: 'I have started at teacher education [to become a primary and lower-secondary school teacher with mathematics as speciality]. I have always wanted to become a teacher'.

Christine's major revision of her narrative seemed surprising. In an interview at the beginning of her teacher education, she explained how she was not sure whether engineering would be the right fit for her, and whether it at all was worth spending four hours on a train each day to go to the technical university. Her relationship with her boyfriend and their new apartment prevented her from moving away from the smaller city she lived in, and the teacher education institution was nearby. Christine's narrative is an example of how students' choices are embedded in their surroundings, that they are influenced by different material and relational components as well as study and career-related considerations, and how choice narratives also have to be aligned with life in general. Even when her choice changed over a short period of time, she managed to negotiate her narrative to keep a sense of stability in her understanding of herself. The phrasing 'I always' indicates a choice well-reasoned, motivated, and stable. Generally, we found that the students often used 'always' in their choice-narratives, but that the 'always' in some cases (as for Christine) was constructed retrospectively in the sense that students used it even when their choice-narrative dramatically changed over time (Holmegaard, Ulriksen, \& Madsen, 2012). To understand what happened in Christine's narrative it is helpful to draw upon narrative psychology.

From the perspectives of narrative psychology we are always situated in the middle of our stories, and since we are not sure how they will turn out, we constantly revise the plot as new events occur and as new perspectives of how these events will turn out become visible (Polkinghorne, 1988). Not only do our perspectives of the future constantly change when new meaning occurs, we also change our narratives retrospectively (Bruner, 1990, 2004). Imagine a car driving on a winding road and as it turns new landscapes become visible not only through the windscreen but also through the rear-view window. Similarly, as our narratives change new perspectives become visible and new episodes from our lives are highlighted. Disruptive elements are removed from the narrative to maintain a degree of meaning and stability (Crossley, 2000), and new elements are added in a process of negotiation and identity work. Another example from the interviews illustrates this perspective. The following are three quotes from Filip's narrative. The first two quotes are from two interviews made during the first semester. The final quote is from an interview during the third semester of his engineering course:

I am looking forward to working on management. How to manage craftsmen when building something (...) People don't think engineers work with humans, but I think they just do it in another way, they work with management. (Filip, studying engineering, 
October 2009)

My professor says: 'Don't focus too much on management. It is too arrogant to enter the labour market as a new engineer and say 'I want to become a leader'. Get some more clear-cut engineering skills instead’. My conclusion is to study energy and then combine it with some management later. It is an important challenge for the world to face in the future (...) I also began recognising that management is also tough and hard work. (Filip, studying engineering, November 2009)

I've been interested in energy for many many years. When I was a kid I found motors to be really cool and later nuclear power. It was really many years ago (...). And now I have learned about how companies work and where in the world is more exiting to work with energy. $\quad$ (Filip, studying engineering, September 2010)

The examples shows how Filip kept on working on and negotiating his narrative about why he studies engineering and his perspectives on doing it, but also on retelling his past rationales for entering the programme. Management as an interest in engineering is negotiated in the narrative from being his major perspective for studying engineering, through management being too tough and hard, and, finally, to become totally excluded. Conversely, energy engineering becomes included in the narrative as a future challenge for the world, and something he has always been interested in. Filip's perception of the future changed from management to energy engineering as he interacted with a cultural norm at the study programme mediated through his professor: 'engineering is about engineering'. As a consequence he changed both his perception of the future in terms of who to become and why (energy engineering being an important challenge in the future) but also his retrospective narrative of why he wanted to become an energy engineer (because he always had been interested). Filip is one example of how culture and norms interact very explicitly with his meaning making and his way of understanding himself. It shows how choices are not well-defined decisions taking place at a certain point in time, but rather ongoing processes of negotiations over time where new meanings, new identities and choices are produced.

\section{Discussion and conclusion}

In this chapter we have shown how narrative theory in general, and narrative psychology in particular, provide lenses to look further into how students make meaning of their choice of study after upper-secondary school. Contrary to research in students' choices aiming at identifying and mapping the variables that affect students' choices, theories about narratives provide a framework to study the complexity when students make choices. Through the theory we get to approach students' construction of their choice-narrative. This includes first of all a focus on the students' making meaning of what a particular study programme would be like and how they relate themselves to that meaning, but also what kind of future they 
recognize as becoming available through a particular study programme. Secondly, the students need to make their choice-narratives recognizable to their surroundings but also to their sense of self. Therefore, their narratives are tried out and negotiated with their social acquaintances where they are informed, adjusted, and revised based on how these acquaintances meet and recognize the choice-narratives as suitable to who they expect the student to be. Finally, the students' narratives are embedded in culturally shared understandings of what a good and proper choice consists of, and in their choice narratives the students need to relate to these truisms in order to be recognized. By applying a narrative psychological approach to students' upper-secondary choices, we can understand students' identity work when they are struggling to find a suitable study programme.

In this chapter we have shown how narrative psychology provides an understanding of choice of study as a process taking place over time where individuals work on their identities in terms of constructing a coherent choice narrative. Choice of study is not an isolated event linked to a formal decision point at a particular time, that is, when students send their application forms listing their desired courses of study. This formal decision point highlights the choice of study for the students, but applying a narrative psychological approach we learn how the choice of study is a continuing process also after entering higher education (see also Chapter 15).

Therefore the findings reached by this approach may differ from the ones reached when using, for instance, the Eccles model. It depends, however, on which version of the Eccles model is used, and what is emphasised. In earlier versions of the model (Eccles, 1983, 1994) the different components of the model (cultural milieu, students' perceptions of socialisers' attitudes, etc.) are linked with one-way arrows that end in achievement related behaviour and choices. These versions suggest that the choice of study is an activity that unfolds through a number of steps to reach the final decision point. Consequently, the model presumes that there is a place in time where the choice is made, and hence that it is possible to map which information, persons, teaching, subjects etc. contributed to the particular choice. However in the later version of the model (Eccles \& Wigfield, 2002) which is the one applied in this book (see Chapter 2) this one-way assumption of choice is modified by a dashed arrow leading from the achievement related choices and behaviour back to a box at the left-hand side of the model referring to 'previous achievement-related experiences'. Hence, the latter version suggest that the process of choice is in fact not a one-time decision, but rather a process where experiences continuously feed into further decisions. Also, the concept of identity has a stronger focus in the later versions of the model (through attainment value).

Narrative psychology emphasises this relation between experiences and decisions and that this is a continuous process. It approaches choice as ongoing identity-work, and hence the way information, persons, teaching, subjects affect the choice depends on how the student makes meaning of it - and that this changes over time. The process of choosing involves an ongoing negotiation of who you 
are (present), who you wish to become (prospective) and how it suits your notion of self (retrospective).

The results that can be reached through narrative psychology contribute with new knowledge on how students' choices are an ongoing process of identity-work being negotiated throughout time. In this book we show how the results reached through this framework supplement findings from previous research, adding a more complex understanding of how students choose to enter a STEM programme or not, and whether to stay or not (see Chapter 21). The findings emphasise a need for caution concerning methodologies in future studies. Firstly, care needs to be taken when interpreting student responses that they always wanted to study a particular subject. Narrative psychology illustrates how we need to contextualize this always in terms of the students current position, context and meaning making. The framework allows for new interpretation of how the students' descriptions of always wanting to study a certain study programme change over time, including after students begin higher education. Secondly, the results reached by applying a narrative psychological framework in this book add to the discussion on previous research which states that students' choices are constructed already in childhood (Archer et al., 2010; Head, 1997). While it is by no means unlikely that many students eventually entering a STEM higher education programme have acquired an interest and inclination towards STEM subjects in the early years of schooling, the point that choices are made over time and involve construction of narratives draws attention to the need for students to be able to continue to construct a viable, recognisable, and convincing narrative through upper-secondary school and beyond. Further, it opens an opportunity to offer students who may not have had access to narratives containing STEM as a possible path of study and career an opportunity to construct such a narrative during upper-secondary school. This, however, presupposes that students' experiences with STEM subjects during upper-secondary school in fact provide the student with material for such a narrative - both in terms of present interest, future perspectives, and the reconstruction of past experiences.

In this chapter we have argued that the choice of study is a continuing process occurring across institutional and cultural contexts. More broadly it could prove fruitful to approach the choice of higher education as a transition process. Previously, transition from upper-secondary school to higher education has been understood as a linear progression from one institution to another (Ecclestone, 2007). But new research suggests approaching such transitions in terms of 'transitions of identities'; a process through which students' ongoing work on their identities to become 'somebody' fits into what they recognise as institutionally and culturally accepted pathways and results in a sense of belonging (Ecclestone, Biesta, \& Hughes, 2010, Holmegaard, Madsen, \& Ulriksen, 2013).

As we have shown in this chapter, narrative psychology can be used as a theoretical approach to studying young people's choice of higher education. Future studies could benefit from combining narrative psychology with an approach that aims at understanding how the narratives are situated within institutional, political, so- 
cial and cultural discourses. In such a framework narrative psychology would be a methodology providing the tools for collecting and interpreting data, and the analysis could draw on a wider array of theoretical approaches to situate the students' identity-work into a larger cultural context.

\section{References}

Andrews, Molly, Squire, Corine, \& Tamboukou, Maria. (2008). Doing narrative research. London: Sage publications.

Archer, Louise, DeWitt, Jennifer, Osborne, Jonathan, Dillon, Justin, Willis, Beatrice, \& Wong, Billy. (2010). 'Doing' science versus 'being' a scientist: Examining 10/11 year old schoolchildren's constructions of science through the lens of identity. Science Education, 94(4), 617-639.

Bergerson, Amy A. (2010). College choice and access to college: moving policy, research and practice to the 21st century. ASHE Higher Education Report (Vol. 35, pp. 1-141 ).

Bruner, Jerome. (1990). Acts of meaning. Cambridge, Massachusetts: Harvard University Press

Bruner, Jerome. (2004). Life as narrative. Social Research 71(3), 691-710.

Brunila, Kristiina, Kurki, Tuuli, Lahelma, Elina, Lehtonen, Jukka, Mietola, Reetta, \& Palmu, Tarja. (2011). Multiple transitions: Educational policies and young people's post-compulsory choices. Scandinavian Journal of Educational Research, 55(3), 307-324.

Crossley, Michele L. (2000). Narrative psychology, trauma and the study of self/identity. Theory \& Psychology, 10(4), 527-546.

Czarniawska, Barbara. (2004). Narratives in Social Science Research London: SAGE Publications Ltd.

Eccles, Jacquelynne S. (1983). Expectancies, Values, and Academic Behaviors. In J. T. Spence (Ed.), Achievement and Achievement Motives. Psychological and Sociological Approaches (pp. 75-146). San Francisco: W. H. Freeman and Company.

Eccles, Jacquelynne S. (1994). Understanding women's educational and occupational choices. Psychology of Women Quarterly, 18(4), 585-609.

Eccles, Jacquelynne S., \& Wigfield, Allan. (2002). Motivational beliefs, values, and goals. Annual Review of Psychology, 53(1), 109-132.

Ecclestone, Kathryn. (2007). Lost and found in transition: the implications of 'identity', 'agency' and 'structure' for educational goals and practices. Paper presented at the Researching transition in lifelong learning, University of Stirling.

Ecclestone, Kathryn, Biesta, Gert, \& Hughes, Martin (Eds.). (2010). Transitions and learning through the lifecourse. London and New York: Routledge.

Ezzy, D. (1998). Theorizing narrative identity. Sociological Quarterly, 39(2), 239-252.

Head, John. (1997). Working with Adolescents: Constructing Identity. Hong Kong: The Falmer Press.

Holland, Dorothy, Lachicotte, Jr. William, Skinner, Debra, \& Cain, Carole. (1998). Identity and agency in cultural worlds. Cambridge, Massachusetts and London: Harvard University Press.

Holmegaard, Henriette Tolstrup. (2013). Students' narratives, negotiations, and choices. A longitudinal study of Danish students' transition process into higher education science, engineering and mathematics. Department of Science Education, IND's skriftserie no26/2012, Copenhagen, ISNN: 1602-2149.

Holmegaard, Henriette Tolstrup, Ulriksen, Lars M., \& Madsen, Lene Møller. (2012). The Process of Choosing What to Study: A Longitudinal Study of Upper Secondary Students' Identity Work When Choosing Higher Education. Scandinavian Journal of Educational Research, 1-20. 
Holmegaard, Henriette Tolstrup, Ulriksen, Lars M., Madsen, Lene Møller. (2013). A journey of negotiation and belonging: Understanding students' transitions into higher education science and engineering. Cultural Studies of Science Education, 1-32.

Hsu, Pei-Ling , Roth, Wolff-Michael , Marshall, Anne , \& Guenette, Francis (2009). To be or not to be? Discoursive resources for (dis-)identifying with science-related careers. Journal of Research in Science Teaching, 46(10), 1114-1136.

Illeris, Knud, Katznelson, Noemi, Simonsen, Birgitte, \& Ulriksen, Lars. (2002). Ungdom, identitet og uddannelse. Frederiksberg: Center for Ungdomsforskning, Roskilde Universitetsforlag.

McAdams, D. (2005). A Psychologist without a Country or Living Two Lives in the Same Story. In G. Y. a. S. Hadley (Ed.), Narrative Identities. London: Jessica Kingsley Publishers.

Paulsen, M. B. (1990). College choice: Understanding student enrollment behavior. In A. H. Education (Ed.), (Vol. 6). Washington, DC: School of Education and Human Development, The George Washington University.

Polkinghorne, Donald E. (1988). Narrative knowing and the human sciences. Albany: State University of New Yorke Press.

Quinn, Jocey. (2010). Rethinking 'failed transitions' to higher education. In K. Ecclestone, G. Biesta \& M. Hughes (Eds.), Transitions and learning through the lifecourse. London and New York: Routledge.

Reay, Diane, David, Miriam E., \& Ball, Stephen. (2005). Degrees of Choice: social class, race and gender in higher education. Oxford.

Ricoeur, Paul. (1976). Interpretation theory: Discourse and the Surplus of Meaning: Texas Christian University Press.

Ricoeur, Paul. (1990). Time and Narrative. London: The University of Chicago Press.

Schreiner, Camilla. (2006). Exploring a ROSE-garden. Norwegian youth's orientations towards science: Seen as signs of late modern identities. (no. 58 Doctoral Thesis), University of Oslo, Oslo.

Schreiner, Camilla, \& Sjøberg, Svein. (2007). Science education and youth's identity construction - two incompatible projects? In J. D. Deborah Corrigan, Richard Gunstone (Ed.), The re-emergence of values in the science. Rotterdam: Sense Publishers.

Smith, B., \& Sparkes, A. C. (2008). Contrasting perspectives on narrating selves and identities: an invitation to dialogue. Qualitative Research in Psychology, 8(5).

Ulriksen, Lars, Holmegaard, Henriette Tolstrup \& Madsen, Lene Møller (2013). Weaving a Bridge of Sense: students' narrative constructions as a lens for understanding students' coping with the gap between expectancies and experiences when entering higher education. European Educational Research Journal, 12(3), 310-319. 